\title{
Peningkatan Kompetensi Pedagogik Guru PAUD dalam Pembuatan Video Pembelajaran Sains Berbasis Smartphone
}

\author{
Noly Shofiyah ${ }^{1}$, Choirun Nisak Aulina ${ }^{2}$, Nur Efendi ${ }^{3}$ \\ 1,3 Pendidikan IPA, FPIP, Universitas Muhammadiyah Sidoarjo; 2, PG-PAUD, FPIP, Universitas \\ Muhammadiyah Sidoarjo \\ e-mail: nolyshofiyah@umsida.ac.id¹, lina@umsida.ac.id², nur.efendi@umsida.ac.id³
}

\begin{abstract}
ABSTRAK. Akibat dari pandemic covid-19, seluruh kegiatan belajar mengajar dari level TK sampai Perguruan tinggi harus dilaksanakan secara daring (online). Namun pembelajaran daring juga menjadi masalah bagi guru karena dituntut untuk berinovasi dalam pengajaran agar siswa tetap belajar sebagaimana mereka lakukan di sekolah. Dalam hal ini, mitra dalam kegiatan ini yaitu TK Aisyiyah 7 Kalidawir dan KB Aisyiyah 8 Putat mengalami kendala dalam hal pembuatan video pembelajaran sains yang kreatif, inovatif dan menarik berbasis smartphone. Oleh karena itu, diselenggarakan kegiatan workshop yang bertujuan untuk meningkatkan kompetensi guru dalam pembuatan video pembelajaran sains AUD. Metode yang digunakan dalam penyampaian inovasi pengetahuan dan keterampilan adalah pengajaran langsung, tanya jawab, dan pemberian proyek. Kegiatan ini dilaksanakan kurang lebih 1 bulan. Selain itu, juga dilakukan pendampingan dan evaluasi dengan pemberian angket kepada para peserta workshop. Hasil dari kegiatan ini adalah keterampilan guru-guru dalam membuat video pembelajaran sains untuk AUD berbasis smartphone dengan aplikasi Kinemaster meningkat. Selain itu, 94 \% guru-guru sangat setuju bahwa materi pelatihan sesuai dengan kebutuhan kerja dan metode yang digunakan bersifat interaktif.
\end{abstract}

Kata Kunci : Video Pembelajaran; Sains AUD; Pembelajaran Daring; Samartphone.

ABSTRACT. As a result of the Covid-19 pandemic, all teaching and learning activities from kindergarten to tertiary level must be carried out through online learning. However, online learning is also a problem for teachers because they are required to innovate in teaching so that students can continue to learn as they do in school. In this case, partners in this activity, namely TK Aisyiyah 7 Kalidawir and KB Aisyiyah 8 Putat experienced the same problems in making creative, innovative and interesting science learning videos based on smartphones. Therefore, a workshop was held which aims to improve teacher competence in making early childhood science learning videos. The methods used in delivering knowledge and skills innovation are direct instruction, question and answer, and project based instruction. In addition, mentoring and evaluation was also carried out by providing questionnaires to workshop participants. This community dedication was carried out for approximately 1 month The result of this activity is that the skills of teachers in making science learning videos for early childhood based on smartphones with the Kinemaster application have increased. In addition, 94\% of the teachers strongly agreed that the training materials were in accordance with their work needs and the methods used were interactive.

Keyword : Tutorial video; Early Childhood Science; Online Learning; Smartphone. 


\section{PENDAHULUAN}

Pandemi Covid-19 yang saat ini sedang melanda dunia termasuk Indonesia membawa dampak perubahan yang besar pada beberapa sektor mulai dari kesehatan, ekonomi, dan tentunya pendidikan [1]. Khususnya pada bidang pendidikan, dibuat suatu kebijakan yaitu seluruh kegiatan belajar mengajar dari tingkat TK sampai Perguruan tinggi harus dilaksanakan melalui pembelajaran jarak jauh. Pembelajaran jarak jauh dinilai sebagai alternative solusi dalam memutus rantai penularan Covid-19.

Pendidikan jarak jauh adalah jenis pendidikan di mana siswa tidak selalu hadir secara fisik di sekolah [2]. Pendidikan jarak jauh sangat bergantung dengan penggunaan internet, sehingga disebut juga sebagai pembelajaran daring. Pembelajaran jarak jauh mempunyai beberapa manfaat diantaranya adalah siswa dapat belajar dimana saja dan kapan saja [3]; menghemat waktu karena siswa tidak perlu melakukan perjalanan dari rumah ke sekolah [4]; dan mempermudah guru membuat materi dimana saja dan kapan saja [5].

Namun dalam implementasinya, pembelajaran daring yang saat ini dilaksanakan menjadi masalah bagi sebagian besar guru karena mereka harus memikirkan strategi bagaimana caranya supaya anak-anak bisa keluar dari zona kebosanan mereka [6]. Teknologi sangat berperan penting dalam pembelajaran daring dimana teknologi akan digunakan sebagai media interaksi serta transfer informasi terkait pembelajaran [7]. Akan tetapi, masih banyak guru yang belum siap dan mahir memanfaatkan teknologi dalam pembelajaran daring. Pembelajaran dengan mengimplementasikan teknologi membuat guru sulit untuk mengoperasikannya.

Mitra dalam kegiatan ini adalah guru-guru KB TK Aisyiyah Kalidawir, Tanggulangin, Sidoarjo yang berjumlah 4 orang dan TK Aisyiyah 6 Durungbedug dengan jumlah 4 guru. 50 \% dari guru tersebut berpendidikan S1 PG-PAUD, namun sebagian lagi berasal dari lulusan non PG-PAUD. Namun terkait denga lamanya pengalaman mengajar, guru-guru tersebut telah memiliki potensi untuk melaksanakan tugasnya secara profesional. Permasalahan yang terjadi pada saat ini adalah mereka dituntuk untuk melakukan pembelajaran daring yang inovatif dan kreatif yang mampu memotivasi siswanya untuk tetap belajar selama pandemic Covid-19.

Berdasarkan hasil pemberian angket melalui google form tentang kesiapan Guruguru di KB TK Aisyiyah Kalidawir dan TK Aisyiyah 6 Durungbedug dalam menghadapi pembelajaran Daring diperoleh informasi bahwa $60 \%$ guru menyatakan siap dalam menghadapi pembelajaran daring. Beberapa hal yang sudah disiapkan oleh guru diantaranya adalah memasang wifi di sekolah, menyediakan paket internet, membuat Rencana Pelaksanaan Pembelajaran Harian (RPPH) untuk pembelajaran jarak jauh, bahan ajar dan media pembelajaran yang akan dibagikan kepada anak-anak dan orang tua, mengkomunikasikan kepada orang tua tentang metode yang akan diterapkan dalam pembelajaran daring. Dalam implementasi pembelajaran daring, guru-guru di sekolah mitra menggunakan aplikasi WhatsApp Group (WAG). Aplikasi WAG dipilih karena anakanak dan orang tua sudah terbiasa menggunakan aplikasi tersebut sehingga lebih mudah untuk mengoperasikannya. WAG digunakan oleh guru-guru untuk membagikan materi dan tugas kepada orang tua dan anak-anak. Materi yang diberikan dapat berupa 
media video pembelajaran yang mengandung beberapa aspek perkembangan anak khusunya perkembangan kognitif, mulai dari konsep bilangan, lambang bilangan, ukuran, huruf, bentuk, pola, warna dan sains. Pada saat pembelajaran, anak-anak harus didampingi oleh orang tua atau seseorang yang dipilih untuk mendampingi anak tersebut. Adapun untuk menilai seluruh kegiatan atau hasil kerja anak-anak dilakukan dengan metode dokumentasi dan portofolio. Setiap hari hasil dokumentasi tersebut harus dilaporkan pada guru kelas.

Pembelajaran sains tidak tercantum di dalam kurikulum PAUD. Namun bukan berarti sains tidak diajarkan pada anak usia dini. Sains di PAUD diintegrasikan dengan bidang lainnya dalam sebuah tema. Tujuan pembelajaran sains di PAUD adalah untuk membantu anak-anak secara aktif memahami pengetahuan tentang apa yang ada di sekitar lingkungan tempat tinggalnya. Tahapan pelaksanaan penggunaan metode eksperimen pada pembelajaran sains bagi anak usia dini melalui dukungan media pembelajaran serta alat dan bahan pembelajaran maka anak akan lebih mudah untuk mengikuti proses pembelajaran[8]. Selama pembelajaran daring, sains dapat diajarkan dengan beberapa cara salah satunya adalah melalui metode pembelajaran eksperimen berbasis belajar di rumah [9]. Sebelum anak-anak diminta untuk melakukan kegiatan eksperimen mandiri di rumah, maka guru dapat membuat video tutorial tentang eksperimen tersebut.

Sukardi \& Rozi menjelaskan bahwa pembelajaran daring di PAUD dapat dilakukan dengan memberikan video pembelajaran kepada anak-anak yang mana video tersebut dapat dibuat sendiri oleh guru maupun didownload dari youtube [10]. Media social youtube menyediakan banyak pilihan video-video pembelajaran anak usia dini yang menarik. Namun, kelemahan video pembelajaran yang diakses dari youtube adalah tidak adanya kehadiran guru kelas dalam video tersebut. Berbeda dengan video pembelajaran yang dibuat sendiri oleh guru kelas, dimana guru dapat mendesain video sesuai dengan tema-tema yang sudah ditentukan dalam kurikulum sekolah. Selain itu, kehadiran guru kelas dalam video tutorial diyakini dapat menjadi pemicu semangat anak-anak untuk tetap belajar [11]. Syafi'i, et al, menambahkan bahwa video pembelajaran yang dikemas dengan guru nampak hadir dalam video pembelajaran menajadikan anak-anak tertarik untuk mempelajarinya [12].

Namun dari hasil wawancara kepada Guru-guru di sekolah mitra yang dilaksanakan pada bulan Desember 2020, menjelaskan bahwa dalam pembuatan video pembelajaran, guru-guru hanya merekam kegiatan yang dilakukan dengan menggunakan camera Hp nya. Mereka tidak memperhatikan aspek kreatif dan inovatif dalam pembuatan video pembelajaran tersebut. Sedangkan dalam pembelajaran sains, guru-guru lebih memilih mengunduh video pembelajaran dari youtube. Dengan adanya perkembangan ilmu pengetahuan dan teknologi, seharusnya guru-guru di sekolah mitra mampu membuat media pembelajaran representatif. Oleh karena itu, kegiatan workshop ini dilakukan dengan tujuan untuk meningkatkan kemampuan pedagogic guru dalam membuat video pembelajaran sains yang inovatif berbasis smartphone dengan menggunakan aplikasi kinemaster. Aplikasi kinemaster dipilih karena 
mempunyai rating tinggi sebesar 4, 5 dalam Google Play Store dan mampu menerima video dengan format apapun [13].

\section{METODE}

Secara keseluruhan, rencana pelaksanaan program peningkatan keterampilan guru PAUD pada kedua mitra dalam pembuatan video pembelajaran Sains AUD berbasis smartphone digambarkan melalui bagan pada gambar 1 .

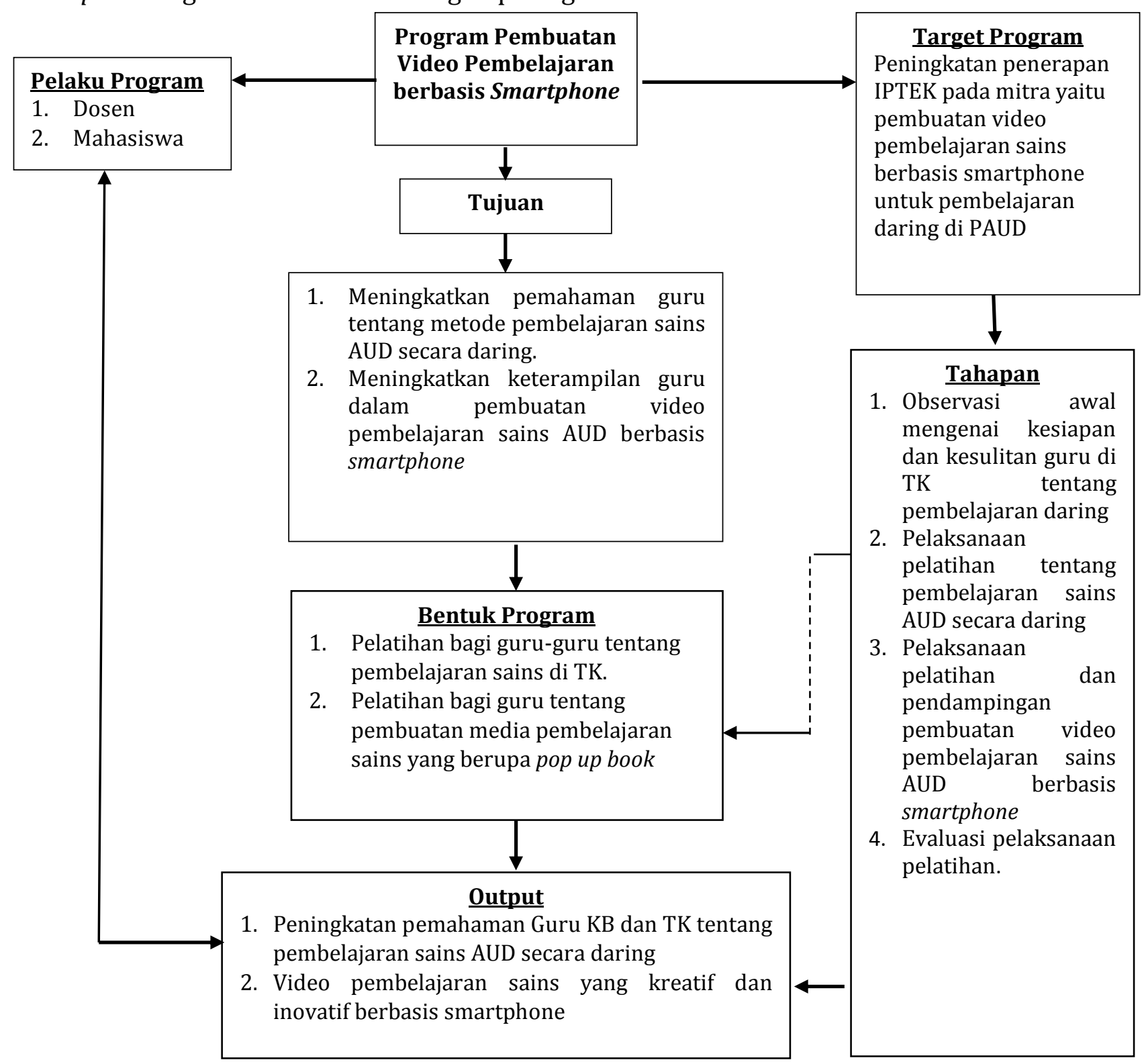

Gambar 1. Rencana Pelaksanaan Program

Transfer IPTEKS yang digunakan dalam kegiatan ini didasarkan pada prinsip bahwa setiap inovasi yang diterima oleh kedua mitra sebaiknya melalui proses melihat dan mendengar; mengetahui; mencoba; mengevaluasi; menerima; dan mengimplementasikan. Sehingga inovasi pengetahuan dan keterampilan yang disampaikan, diharapkan dapat diadopsi oleh mitra secara berkesinambungan. Selain 
itu, kedua mitra diharapkan dapat mengembangkan IPTEK yang telah dikuasainya. Oleh karena itu, penyampaian IPTEK kepada kedua mitra dilaksanakan melalui tahapantahapan sebagai berikut:

1. Penjelasan

Pada tahap ini, guru-guru PAUD diberikan pengetahuan tentang contoh-contoh pembelajaran sains AUD, metode pembelajaran sains daring pada AUD, apa itu aplikasi kinemaster, fitur-fitur pada aplikasi kinemaster beserta fungsinya, serta langkahlangkah dalam membuat video pembelajaran dengan menggunakan aplikasi kinemaster.

2. Diskusi

Pada tahap diskusi, guru-guru diberikan kesempatan untuk bertanya kepada para pemateri terkait dengan pembelajaran sains di PAUD dan pembuatan video pembelajaran berbasis aplikais kinemaster. Diskusi tidak hanya dilakukan pada sesi penyampaian materi, namun juga pada sesi praktek dan pendampingan.

3. Praktek

Setelah penyampaian IPTEK melalui penjelasan kepada para peserta, selanjutnya peserta diminta untuk mempraktekan bagaimana membuat video pembejaran yang menarik berbasis smartphone dengan menggunakan aplikasi kinemaster pada tema Sains.

4. Pendampingan.

Pendampingan diberikan kepada kedua mitra tidak hanya pada saat pelatihan berlangsung yaitu pada saat guru-guru melakukan praktek membuat video pembelajaran dengan aplikasi kinemaster saja. Akan tetapi, pendamdingan juga diberikan pada saat guru-guru akan mengimplementasikan video dalam pembelajaran daring dengan anak-anak.

\section{HASIL DAN PEMBAHASAN}

Pelaksanaan program Peningkatan Kompetensi Pedagogik Guru PAUD dalam Pembuatan Video Pembelajaran Sains AUD berbasis Smartphone telah selesai dilakukan. Kegiatan pelatihan tersebut dilaksanakan pada hari Kamis dan Jum'at, 21-22 Januari 2021 di TK Aisyiyah 8 Kalidawir dan TK Aisyiyah 6 Durung Bedug. Tabel 1 merupakan hasil-hasil yang telah dicapai dalam kegiatan ini.

Tabel 1 Hasil Capaian PKM

\begin{tabular}{|c|c|c|}
\hline Persiapan & & \\
\hline Jenis Kegiatan & Tujuan & Hasil \\
\hline $\begin{array}{l}\text { Pembentukan panitia } \\
\text { pelaksana PKM }\end{array}$ & $\begin{array}{l}\text { Menyusun struktur } \\
\text { kepanitiaan Program } \\
\text { beserta pembagian } \\
\text { deskripsi kerja agar } \\
\text { kegiatan dapat berjalan } \\
\text { lancar }\end{array}$ & $\begin{array}{l}\text { Terbentunya struktur panitia } \\
\text { program yang terdiri dari tim } \\
\text { pelaksana dan tim teknis yang } \\
\text { berasal dari dosen dan } \\
\text { mahasiswa pendidikan IPA } \\
\text { dan PAUD }\end{array}$ \\
\hline $\begin{array}{l}\text { Koordinasi dengan } \\
\text { Pihak TK }\end{array}$ & $\begin{array}{l}\text { Membuat kesepakatan } \\
\text { waktu pelatihan }\end{array}$ & Jadwal Kegiatan \\
\hline Pembuatan & Mengelola kegiatan dan & - Angket Respon terhadap \\
\hline
\end{tabular}




\begin{tabular}{|c|c|c|}
\hline Administrasi Kegiatan & bukti pelaksanaan kegiatan & $\begin{aligned} & \text { pelatihan } \\
- & \text { Banner } \\
- & \text { Presensei } \\
- & \text { Pelatihan KIT }\end{aligned}$ \\
\hline \multirow[t]{3}{*}{ Penyusunan Materi } & \multirow{3}{*}{$\begin{array}{l}\text { Menyusun materi-mateei } \\
\text { dan modul yanga akan } \\
\text { diberikan bagi peserta } \\
\text { pelatihan }\end{array}$} & $\begin{array}{l}\text { Materi pelatihan meliputi: } \\
-\quad \text { Pembelajaran Sains AUD }\end{array}$ \\
\hline & & 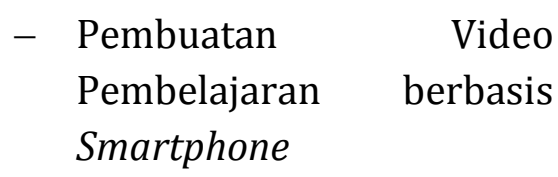 \\
\hline & & $\begin{array}{l}\text { - Modul pembuatan video } \\
\text { pembelajaran dengan } \\
\text { Kinemaster }\end{array}$ \\
\hline
\end{tabular}

\section{Pelaksanaan} Jenis Kegiatan Tujuan Hasil

Kamis, 21 Januari 2021 (TK Aisyiyah 8 Kalidawir)

\begin{tabular}{|c|c|c|}
\hline Pelaksanaan pelatihan &  & $\begin{array}{l}\text { Pengetahuan Guru tentang: } \\
\text { - } \text { Pembelajaran Sains AUD } \\
\text { - } \text { Pembuatan Video berbasis } \\
\text { smartphone dengan } \\
\text { aplikasi Kinemaster }\end{array}$ \\
\hline Pendampingan & $\begin{array}{l}\text { Melaksanakan } \\
\text { pendampingan pada guru } \\
\text { dalam membuat video } \\
\text { pembelajaran } \\
\text { menggunakan dengan } \\
\text { kinemaster }\end{array}$ & $\begin{array}{lr}\text { Guru menghasilkan } & \text { video } \\
\text { pembelajaran } & \text { dengan } \\
\text { menggunakan } & \text { aplikasi } \\
\text { kinemaster } & \end{array}$ \\
\hline $\begin{array}{l}\text { Pemberian } \\
\text { Respon }\end{array}$ & $\begin{array}{l}\text { Mengetahui respon peserta } \\
\text { terhadap pelatihan dan } \\
\text { pendampingan } \\
\text { dilakukan }\end{array}$ & $\begin{array}{l}\text { Respon guru terhadap } \\
\text { pelatihan pembuatan video } \\
\text { pembelajaran } \quad \text { berbasis } \\
\text { smartphone dengan aplikasi } \\
\text { kinemaster }\end{array}$ \\
\hline
\end{tabular}

Jenis Kegiatan

Tujuan

Hasil

Jum'at, 22 Januari 2021 (TK Aisyiyah 6 Durung Bedug)

Pelaksanaan pelatihan Melaksanakan pelatihan Pengetahuan Guru tentang: tentang:

- Pembelajaran Sains AUD

- Pembelajaran Sains - Pembuatan Video berbasis

AUD

- Pembuatan Video smartphone dengan berbasis smartphone dengan aplikasi

Kinemaster 


\begin{tabular}{|c|c|c|c|}
\hline & & $\begin{array}{lr}\text { pendampingan pada guru } \\
\text { dalam membuat video } \\
\text { pembelajaran } & \text { dengan } \\
\text { menggunakan } & \text { aplikasi } \\
\text { kinemaster } & \\
\end{array}$ & $\begin{array}{l}\text { pembelajaran } \\
\text { menggunakan } \\
\text { kinemaster }\end{array}$ \\
\hline $\begin{array}{l}\text { Pemberian } \\
\text { Respon }\end{array}$ & Angket & $\begin{array}{l}\text { Mengetahui respon peserta } \\
\text { terhadap pelatihan dan } \\
\text { pendampingan } \\
\text { dilakukan }\end{array}$ & $\begin{array}{l}\text { Respon guru terhadap } \\
\text { pelatihan pembuatan video } \\
\text { pembelajaran } \quad \text { berbasis } \\
\text { smartphone dengan aplikasi } \\
\text { kinemaster }\end{array}$ \\
\hline
\end{tabular}

Berdasarkan tabel 1, diketahui bahwa kegiatan peningkatan kompetensi pedagogik guru PAUD dibagi menjadi dua tahap yaitu tahap persiapan dan pelaksanaan. Pada tahap persiapan, dibentuk tim panitia pelaksana beserta pembagian job description dan koordinasi dengan mitra 1 dan mitra 2. Koordinasi dilakukan untuk mendapatkan suatu kesepakatan tentang jadwal, tempat, dan metode pelaksanaan program. Sehingga diperoleh hasil bahwa kegiatan pelatihan dilaksanakan selama 2 hari yaitu kamis dan jum'at, 21-22 Januari 2021 mulai pukul 09.00 - 14.00 di TK Aisyiyah 8 Kalidawir. Metode pelatihan yang digunakan adalan tatap muka dengan tetap menerapkan protocol kesehatan pandemic Covid-19. Metode tatap muka dipilih karena guru-guru pada sekolah mitra berjumlah kurang dari 20 sehingga dimungkinkan untuk mengatur jarak antar peserta yang satu dengan peserta yang lain sejauh 1 meter. Pertimbangan lain untuk dilaksanakannya pelatihan secara tatap muka adalah, guru-guru akan mendapatkan pendampingan langsung terkait prosedur merekam video pengajaran menggunakan greenscreen yang sesuai untuk dijadikan sebagai video pembelajaran nantinya. Parda, et., al menjelaskan bahwa pelatihan yang dilaksanakan secara daring kurang efektif karena peserta kurang komunikatif [14]. Tahap persiapan ini juga digunakan untuk menyusun modul pelatihan dan materi-materi pelatihan lainnya.

Selanjutnya, tahap pelakasanaan dibagi menjadi tiga kegiatan yaitu kegiatan pelaksanaan pelatihan, pendampingan dan evaluasi. Kegiatan pelaksanaan pelatihan merupakan kegiatan penyampaian inovasi pengetahuan dan keterampilan kepada mitra yaitu guru-guru PAUD. Pengetahuan yang disampaikan adalah inovasi pembelajaran sains daring untuk AUD dan keterampilan membuat video pembelajaran yang inovatif berbasis smartphone menggunakan aplikasi kinemaster. Aplikais kinemaster dipilih sebagai media dalam membuat video pembelajaran karena mempunyai fitur yang cukup lengkap untuk mengedit video, operasional fitur-fiturnya tergolong mudah, video yang dihasilkan terlihat professional, serta video KineMaster dapat langsung dibagikan ke platform media sosial seperti YouTube, WhatsApp, Facebook, Google+ [15]. Pendampingan merupakan kegiatan pemberian bimbingan kepada peserta pelatihan dalam merekam video pengajaran guru menggunakan camera smartphone dan green screen serta mengedit rekaman video dengan menggunakan aplikasi kinemaster. 




Gambar 2. Pelatihan di TK Aisyiyah 8 Kalidawir

Setelah kegiatan pelatihan dan pendampingan selesai, dilakukan kegiatan evaluasi. Teknik evaluasi terhadap kegiatan dilakukan dengan cara pemberian angket pada peserta pelatihan untuk mengetahui tanggapan peserta terhadap kegiatan pelatihan pembuatan video pembelajaran berbasis samartphone dengan aplikasi kinemaster. Angket yang digunakan mengacu pada tiga indikator yaitu materi, metode dan kebermanfaatan pelatihan. Hasil dari pengisian angket dapat dilihat pada tabel 2.

Tabel 2 Hasil Respon Peserta

\begin{tabular}{|c|c|c|c|c|c|c|}
\hline No. & Pernyataan & SS & $\mathbf{S}$ & $\mathbf{N}$ & TS & STS \\
\hline \multicolumn{7}{|c|}{ Materi Pelatihan } \\
\hline 1 & $\begin{array}{l}\text { Materi pelatihan yang saya ikuti sesuai dengan } \\
\text { kebutuhan kerja }\end{array}$ & $100 \%$ & - & - & - & - \\
\hline 2 & $\begin{array}{l}\text { Materi pelatihan yang saya ikuti sesuai dengan } \\
\text { tujuan pelatihan }\end{array}$ & $100 \%$ & - & - & - & - \\
\hline 3 & $\begin{array}{l}\text { Materi pelatihan yang saya ikuti disampaikan } \\
\text { dengan menarik dan dibahas secara mendalam }\end{array}$ & $75 \%$ & $25 \%$ & - & - & - \\
\hline 4 & $\begin{array}{l}\text { Materi pelatihan yang saya ikuti dapat } \\
\text { memberikan manfaat secara pengetahuan dan } \\
\text { keterampilan dibidang pekerjaan saya }\end{array}$ & $100 \%$ & - & - & - & - \\
\hline \multicolumn{7}{|c|}{ Metode Pelatihan } \\
\hline 5 & $\begin{array}{l}\text { Instruktur pelatihan yang saya ikuti dapat } \\
\text { berinteraksi dengan baik kepada saya dan peserta } \\
\text { lainnya }\end{array}$ & $75 \%$ & $25 \%$ & - & - & - \\
\hline 6 & $\begin{array}{l}\text { Instruktur pelatihan yang saya ikuti memberikan } \\
\text { kesempatan kepada saya dan peserta lainnya } \\
\text { untuk bertanya }\end{array}$ & $100 \%$ & - & - & - & - \\
\hline 7 & $\begin{array}{l}\text { Instruktur pelatihan yang saya ikuti } \\
\text { menyampaikan materi pelatihan dengan jelas dan } \\
\text { mudah dipahami }\end{array}$ & $100 \%$ & - & - & - & - \\
\hline 8 & $\begin{array}{l}\text { Instruktur pelatihan yang saya ikuti dapat } \\
\text { menguasai materi yang diajarkan }\end{array}$ & $100 \%$ & - & - & - & - \\
\hline 9 & $\begin{array}{l}\text { Instruktur pelatihan yang saya ikuti dapat } \\
\text { mendorong saya dan para peserta lainnya aktif } \\
\text { dalam kegiatan pelatihan }\end{array}$ & $100 \%$ & - & - & - & - \\
\hline 10 & Instruktur pelatihan yang saya ikuti selalu siap & $75 \%$ & $25 \%$ & - & - & - \\
\hline
\end{tabular}


membantu peserta selama pelatihan berlangsung

\begin{tabular}{|c|c|c|c|c|c|c|}
\hline \multicolumn{7}{|c|}{ Kebermanfaatan Pelatihan } \\
\hline 11 & $\begin{array}{l}\text { Pengetahuan dan keterampilan saya tentang } \\
\text { pembuatan video pembelajaran meningkat }\end{array}$ & $100 \%$ & - & - & - & - \\
\hline 12 & $\begin{array}{l}\text { Pengetahuan dan keterampilan saya tentang } \\
\text { operasionalisasi aplikasi kinemaster meningkat }\end{array}$ & $100 \%$ & - & - & - & 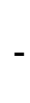 \\
\hline 13 & $\begin{array}{l}\text { Setelah pelatihan saya mampu membuat video } \\
\text { pembelajaran dengan aplikasi kinemaster }\end{array}$ & $100 \%$ & - & - & - & - \\
\hline
\end{tabular}

Berdasarkan tabel 2 dapat disimpulkan bahwa para peserta 93,75 \% menyatakan sangat setuju dan 6,25 \% setuju bahwa materi pelatihan yang diberikan sesuai dengan bidang pekerjaan mereka, memberikan manfaat secara pengetahuan dan keterampilan dibidang pekerjaan mereka serta menarik untuk dibahas lagi secara mendalam. Pelatihan pembuatan video bagi guru PAUD juga mampu meningkatkan sikap percaya diri dan motivasi dalam menggunakan teknologi [16]. Selain itu, $100 \%$ para peserta juga setuju bahwa metode pelatihan yang digunakan sangat interaktif dan mampu memotivasi para peserta. Selanjutnya, 91,67 \% peserta menyatakan sangat setuju dan 8,33\% menyatakan setuju bahwa pemateri dan fasilitator pelatihan menguasai materi, menyampaikan materi dengan jelas dan mudah dipahami, memberikan kesempatan peserta untuk bertanya, dan memotivasi peserta untuk aktif dalam kegiatan. Selain itu, $100 \%$ peserta sangat setuju bahwa pelatihan yang diberikan dapat meningkatkan pengetahuan dan keterampilan mereka dalam membuat video pembejaran dengan aplikasi kinemaster. Hal tersebut juga diungkapkan oleh Ismanto bahwa pelatihan penggunaan smartphone android sebagai media pembelajaran bagi guru SMA Negeri 2 Kota Pekanbaru mampu meningkatkan pengetahuan mereka dalam bidang pengembangan teknologi informasi pendidikan [17]. Beberapa komentar yang diberikan oleh peserta adalah terkait durasi pelatihan yang kurang lama dan diharapkan adanya pelatihan lagi tentang metode-metode pembelajaran AUD yang menarik.

Kegiatan ini dapat terlaksana dengan baik karena adanya dukungan dari mitra yaitu tersedianya tempat pelatihan, sarana dan prasarana serta keaktifan peserta pada saat pelatihan. Para peserta dengan aktif mengikuti pelatihan mulai dari penyampaian materi, pembuatan video sampai pengeditan video menggunakan aplikasi kinemaster. Namun beberapa peserta menghadapi kendala yaitu kurang besarnya space device yang dimiliki, sehingga hanya beberapa guru saja yang bisa menyelesaikan pembuatan video pembelajaran berbasis smartphone dengan menggunakan aplikasi kinemaster. Sebagaimana yang dijelaskan oleh Puryono [18] bahwa salah satu kekurangan aplikasi kinemater adalah dapat berjalan dengan lancar tanpa lag, jika smartphone yang digunakan mempunyai spesifikasi ram 2 GB ke atas.

\section{KESIMPULAN}

Berdasarkan uraian pada pembahasan diketahui bahwa melalui kegiatan pengabdian ini, guru-guru di TK Aisyiyah 8 Kalidawir dan TK Aisyiyah 6 Durung Bedug mampu membuat video pembelajaran sains untuk AUD berbasis smartphone dengan 
aplikasi Kinemaster dengan baik. Selain itu, 94 \% guru-guru di TK Aisyiyah 8 Kalidawir dan TK Aisyiyah 6 Durung Bedug sangat setuju bahwa pelatihan pembuatan video pembelajaran sains AUD berbasis smartphone dengan aplikasi kinemaster sangat sesuai dengan kondisi saat pandemic covid-19 ini. Sebagai tambahan, guru-guru dapat berlatih lagi secara mandiri melalui modul pembuatan video pembelajaran "Kinemaster" yang sudah diberikan. Selain itu, guru-guru dapat mebuat rekaman video menggunakan green screen yang telah diberikan dengan lebih kreatif lagi.

\section{PENGHARGAAN}

Terima kasih disampaikan kepada seluruh pihak yang membantu terselenggaranya kegiatan ini. Pihak-pihak tersebut diantaranya dalah Universitas Muhammadiyah Sidoarjo yang telah memberikan hibah bantuan PKM-C19, Mitra yaitu Guru-guru TK Aisyiyah 8 Kalidawir dan TK Aisyiyah 6 Durung Bedug yang berpartisipasi aktif dalam kegiatan, serta seluruh panitia pelaksana baik Dosen maupun mahasiswa.

\section{REFERENSI}

[1] M. Siahaan, "Dampak Pandemi Covid-19 Terhadap Dunia Pendidikan," J. Kaji. Ilm., vol. 1, no. 1, pp. 73-80, 2020.

[2] M. Sadeghi, "Manijeh Sadeghi 1," Int. J. Reserach Englissh, vol. 4, no. 1, pp. 80-88, 2019.

[3] A. G. Picciano, "Theories and frameworks for online education: Seeking an integrated model," Online Learn. J., vol. 21, no. 3, pp. 166-190, 2017.

[4] M. M. S. de Oliveira, A. S. T. Penedo, and V. S. Pereira, "Distance education: advantages and disadvantages of the point of view of education and society," Dialogia, no. 29, pp. 139-152, 2018.

[5] S. A. Nugraha, T. Sudiatmi, and M. Suswandari, "Studi Pengaruh Daring Learning Terhadap Hasil Belajar Matematika Kelas IV," J. Inov. Penelit., vol. 1, no. 3, pp. 265276, 2020.

[6] A. Anugrahana, "Hambatan, Solusi dan Harapan: Pembelajaran Daring Selama Masa Pandemi Covid-19 Oleh Guru Sekolah Dasar," Sch. J. Pendidik. dan Kebud., vol. 10, no. 3, pp. 282-289, 2020.

[7] U. Hanifah Salsabila, L. Irna Sari, K. Haibati Lathif, A. Puji Lestari, and A. Ayuning, "Peran Teknologi Dalam Pembelajaran Di Masa Pandemi Covid-19," Al-Mutharahah J. Penelit. dan Kaji. Sos. Keagamaan, vol. 17, no. 2, pp. 188-198, 2020.

[8] F. F. Hikam and E. Nursari, "Analisis Penggunaan Metode Eksperimen Pada Pembelajaran Sains Bagi Anak Usia Dini," Murhum J. Pendidik. Anak Usia Dini, no. 2, pp. 38-49, 2020.

[9] H. Nafiqoh and G. Wulansuci, "Mengembangkan Sikap Sains Anak Usia Dini Melalui Metode Pembelajaran Eksperimen Berbasis Belajar Dari Rumah,” J. Tunas Siliwangi, vol. 6, no. 2, pp. 98-104, 2020.

[10] S. Sukardi and F. Rozi, "Pengaruh Model Pembelajaran Online Dilengkapi Dengan Tutorial Terhadap Hasil Belajar," JIPI (Jurnal Ilm. Penelit. dan Pembelajaran Inform., vol. 4, no. 2, p. 97, 2019.

[11] E. Suhendro, "Strategi Pembelajaran Pendidikan Anak Usia Dini di Masa Pandemi Covid-19," Golden Age J. Ilm. Tumbuh Kembang Anak Usia Dini, vol. 5, no. 3, pp. 133-140, 2020. 
[12] I. Syafi'i, C. Sa'diyah, E. W. Wakhidah, and F. M. Umah, "Penerapan Video Pembelajaran Daring Anak Usia Dini Pada Masa Pandemi Covid-19," Al-Athfaal J. Ilm. Pendidik. Anak Usia Dini, vol. 3, no. 2, pp. 140-160, 2020.

[13] Ermanto and Zulfadhli, "Peningkatan Kemampuan Publikasi Jurnalistik Perangkat Nagari Menggunakan Aplikasi KineMaster untuk Media Sosial di Nagari Tuik IV Koto Mudiek dan Nagari Sungai Nyalo IV Koto Mudiek Kecamatan Batang Kapas Kabupaten Pesisir Selatan melalui Pelatihan," Abdi Humanora J. Pengabdi. Masy. Bid. Hum., vol. 1, no. 1, pp. 9-13, 2019.

[14] R. T. Sataloff, M. M. Johns, and K. M. Kost, "Pelatihan Budidaya Tanaman Kangkung Hidroponik Dengan Memanfaatkan Barang Bekas Pada Masyarakat RT 04, RW 06, Desa Kalijurang, Kecamatan Tonjong, Kabupaten Brebes."

[15] H. Khaira, "Pemanfaatan Aplikasi Kinemaster Sebagai Media Pembelajaran Berbasis ICT," in Prosiding Seminar Nasional PBSI-III Tahun 2020, 2020, pp. 39-44.

[16] W. E. Hardiyanti, M. Ilham, W. Ekadayanti, and J. Jafarudin, "Pelatihan Pembuatan Video Animasi Gambar 'Powtoon' bagi Guru PAUD," Abdimas Pedagog. J. Ilm. Pengabdi. Kpd. Masy., vol. 3, no. 2, pp. 78-86, 2020.

[17] E. Ismanto, M. Novalia, and P. B. Herlandy, "Pemanfaatan Smartphone Android Sebagai Media Pembelajaran Bagi Guru Sma Negeri 2 Kota Pekanbaru," J. Pengabdi. UntukMu NegeRI, vol. 1, no. 1, pp. 42-47, 2017.

[18] D. A. Puryono, "Pelatihan Pembuatan Video Pembelajaran Untuk Guru Sd Kristen Terang Bagi Bangsa Pati Menggunakan Kinemaster," J. Pengabdi. Vokasi, vol. 01, no. 04, pp. 242-247, 2020. 